\title{
Paraorientatractis semiannulata n. g., n. sp. (Cosmocercoidea: Atractidae) from the Large Intestine of the Side-Necked Turtle, Podocnemis unifilis Troschel, 1848 (Testudines: Pelomedusidae) in Brazil
}

\author{
Lynda M Gibbons/+ , LF Khalil, CJ Marinkelle* \\ International Institute of Parasitology, CAB INTERNATIONAL, 395A Hatfield Road, St Albans, Herts AL4 \\ 0XU, UK *Universidad de los Andes, Apartado Aéreo 4976, Bogota, Colombia
}

Specimens collected from the large intestine of the side-necked turtle Podocnemis unifilis Troschel, 1848 in the region of Cuminá and Trombetas rivers near Pará, Brazil are assigned to a new genus and new species of the nematode superfamily Cosmocercoidea and family Atractidae and named Paraorientatractis semiannulata. The new genus is separated from the nearest genus Orientatractis by the funnel-shaped mouth opening, the presence of 4 distinct lips, 4 papillae in the internal cycle, one on each lip margin, 2 lateral amphids with large amphidial pores and absence of submedian papillae. It is also separated from Orientatractis and Proatractis by the presence of striated lateral alae which curve dorsally extending from mid oesophagus to mid tail, the difference in size of the vulvar opening and the presence of large transverse ridges or semiannules on the dorsal surface. The new species can be separated from the species of the genera Orientatractis and Proatractis by the characters that distinguish the genera and the arrangement of the caudal papillae on the male. A host/parasite list for Podocnemis spp. is included.

Key words: Nematoda - Atractidae - Paraorientatractis n. g. - Paraorientatractis semiannulata n. sp. Podocnemis - Brazil

The genus Podocnemis Wagler, 1830 accomodates turtles referred to as the hidden-necked turtles or side-necked turtles found in South American rivers. The genus belongs to the order Testudines and the family Pelomedusidae. A survey undertaken by one of us (CJM) in the region of the Cuminá and Trombetas rivers near Pará, Brazil resulted in the collection of large numbers of an atractid nematode from the large intestine of Podocnemis unifilis. Nine species of nematodes have so far been reported from Podocnemis spp. (Table). A comparison of the specimens described herein with the species listed revealed that they had distinct differences which separated them from these species and consequently a new genus and new species are proposed to accomodate them.

\section{MATERIALS AND METHODS}

Nematode specimens collected from the large intestine of the turtles, $P$. unifilis were fixed by dipping them in steaming $70^{\circ} \mathrm{GL}$ alcohol and were subsequently stored in $70^{\circ} \mathrm{GL}$ alcohol. Specimens

${ }^{+}$Corresponding author. Fax: +44-1727-86.8721

Received 4 December 1996

Accepted 19 February 1997 were later cleared in lactic acid or lactoglycerol and some were stained in Horen's Trichrome stain and cleared in lactophenol. One male was mounted in Berlese's fluid to examine the spicules and the gubernaculum. A male and female, cleared in glycerine/alcohol, were hand-sectioned using a razor blade and each section was mounted in glycerine jelly to examine the lateral alae. En face preparations were made with the head region of the two specimens. Nineteen specimens were prepared for examination by the scanning electron microscope using the critical point drying technique with liquid carbon dioxide as the drying medium. The dried specimens were coated with gold. An Olympus BH2 interference microscope was used for light microscopy and drawings were made with the aid of a drawing tube. Type specimens are deposited in the type collection of the International Institute of Parasitology. Measurements are in millimetres unless otherwise stated.

\section{RESULTS}

Description: Paraorientatractis n. g.

Diagnosis

Atractidae. Body elongate, attenuated, coiled, transversally striated with semiannules on the dorsal surface. Well developed longitudinally ridged 
TABLE

Nematodes from Podocnemis spp.

\begin{tabular}{|c|c|c|c|}
\hline$\underline{\text { Parasite }}$ & Host & Locality & Reference \\
\hline Paratractis hystrix & $\begin{array}{l}\text { P. erythrocephala } \\
\text { P. dumeriliana } \\
\text { P. vogli } \\
\text { P. expansa } \\
\text { P. unifilis }\end{array}$ & $\begin{array}{l}\text { Brazil } \\
\text { Peru } \\
\text { Colombia } \\
\text { Colombia } \\
\text { Colombia }\end{array}$ & $\begin{array}{l}\text { Diesing } 1851 \\
\text { Sarmiento } 1959 \\
\text { Buckley } 1970 \\
\text { Khalil \& Gibbons } 1988 \\
\text { Khalil \& Gibbons } 1988 \\
\text { Khalil \& Gibbons } 1988\end{array}$ \\
\hline Buckleyatractis marinkelli & P. unifilis & Colombia & Khalil \& Gibbons 1988 \\
\hline Podocnematractis colombiaensis & $\begin{array}{l}\text { P. expansa } \\
P . \text { vogli }\end{array}$ & $\begin{array}{l}\text { Colombia } \\
\text { Colombia }\end{array}$ & $\begin{array}{l}\text { Gibbons et al. } 1995 \\
\text { Gibbons et al. } 1995\end{array}$ \\
\hline Podocnematractis ortleppi & $\begin{array}{l}\text { P. unifilis } \\
\text { P. expansa } \\
P . \text { vogli }\end{array}$ & $\begin{array}{l}\text { London Zoo (?),UK } \\
\text { Colombia } \\
\text { Colombia }\end{array}$ & $\begin{array}{l}\text { Thapar } 1925 \\
\text { Gibbons et al. } 1995 \\
\text { Gibbons et al. } 1995\end{array}$ \\
\hline Atractis conciliatus & P. expansa & Brazil & Alho 1964 \\
\hline Orientatractis leiperi & P. vogli & Colombia & Buckley 1969 \\
\hline Ancyracanthus pinnatifidus & $\begin{array}{l}\text { P. expansa } \\
\text { P. dumeriliana }\end{array}$ & $\begin{array}{l}\text { Brazil } \\
\text { Brazil }\end{array}$ & $\begin{array}{l}\text { Gomes \& Kohn } 1970 \\
\text { Gomes \& Kohn } 1970\end{array}$ \\
\hline Serpinema amazonicus & P. expansa & Brazil & Ribeiro 1941 \\
\hline "Spirurids" & P. unifilis & Brazil & Travassos \& Freitas 1964 \\
\hline
\end{tabular}

lateral alae. Tail of both sexes ends in a caudal appendix. Mouth opening terminal, funnel-shaped, with four lips, each lip with a single papilla, a pair of recurved spines which appear to be joined at the base and a single median spine near the distal margin. Two large lateral amphids with a pair of small spines posterior to the amphidial pore. Cervical papillae rounded, project only slightly from body surface. Oesophagus divided. Excretory pore opens into an elongate chamber just anterior to the distal bulb of the oesophagus. Eight pairs of male caudal papillae, four pairs precloacal, four pairs postcloacal and a pair of phasmids. Spicules unequal, pointed at distal tips. Gubernaculum present. Vulva, small, opens close to anus. Viviparous. Adults parasitic in the large intestine of freshwater turtles. Type species $P$. semiannulata $\mathrm{n}$. sp.

\section{Paraorientatractis semiannulata n. sp.} (Figs 1-19)

Morphometrics: based on seven males and eight females.

Body curved when fixed with ridged lateral alae which curve dorsally, margin of lateral alae markedly extended dorsally in mid body. Dorsal surface with large transverse ridges or half annules extending between the lateral alae, absent on the ventral surface. Anterior end bluntly rounded, cephalic region slightly wider than anterior cervical region. Mouth opening terminal with four lips, each lip with a single papilla of the inner circle of cephalic sensory organs, submedian papillae absent, two large lateral amphids present. Each lip has a pair of recurved pointed spines near their proximal margin which appear to join at the base and a single median spine near the distal margin. A pair of smaller spines are seen posterior to the amphidial pores. The lips form a funnel shaped opening which was seen in all the specimens examined. The oesophagus is distinctly divided and the excretory pore opens in the middle of a disc-like structure. The excretory pore opens into an elongate chamber. The tail of both sexes ends in an elongate appendix.

Male: body $2.35-2.52$ long, $0.05-0.06$ wide just anterior to the cloaca; head $0.03-0.033$ wide; buccal cavity 0.010 - 0.015 long; excretory pore, cervical papillae and nerve ring $0.28-0.30,0.160$ - 0.181 and $0.170-0.191$ from the anterior end respectively; anterior muscular oesophagus 0.138 - 0.153 long, posterior glandular oesophagus 0.206 - 0.225 long; large half annules on the dorsal surface commence $0.155-0.168$ from anterior end and extend to $0.12-0.18$ posterior to the cloaca; lateral alae arise $0.185-0.235$ from anterior end and finish $0.12-0.18$ posterior to the cloaca; spicules unequal, finely pointed, right spicule 0.086 0.118 long, left spicule 0.220 - 0.340 long; gubernaculum $0.040-0.054$ long S-shaped in lateral view. Caudal papillae arranged as follows: three 


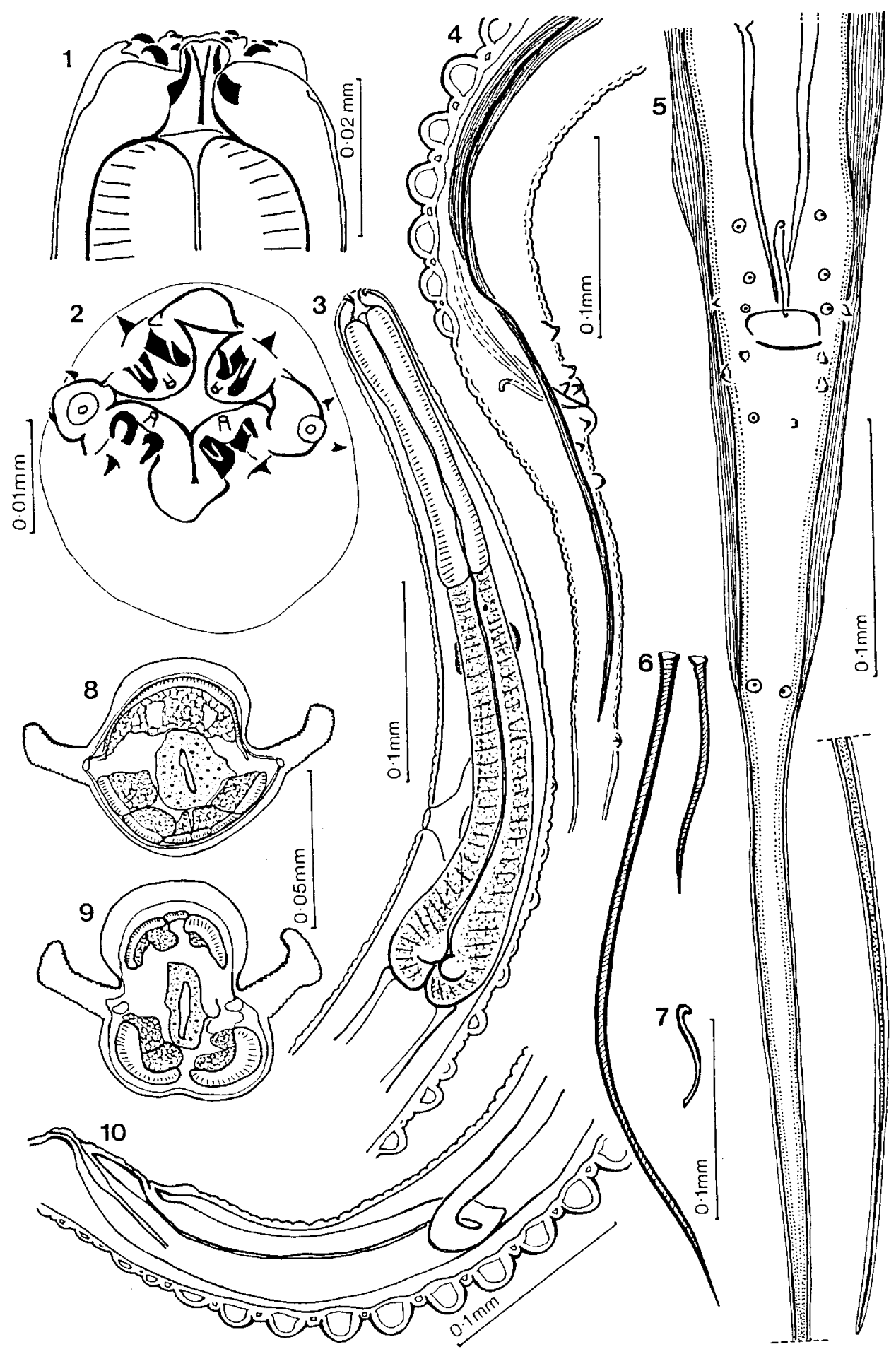

Figs 1-10: Paraorientatractis semiannulata n. g., n. sp., light microscopy. 1: anterior end of male, lateral view. 2: en face view of cephalic region of male. 3: anterior end of female showing oesophagus and position of excretory pore, lateral view 4: male showing structures around the cloacal region, lateral view. 5: posterior end of male ventral view. 6: male spicules dissected out of body. 7: gubernaculum dissected out of body, lateral view. 8: cross section through middle of body of male, orientated dorso-ventrally. 9: cross section through middle of body of female, orientated dorso-ventrally. 10: vulvar region of female, lateral view. 

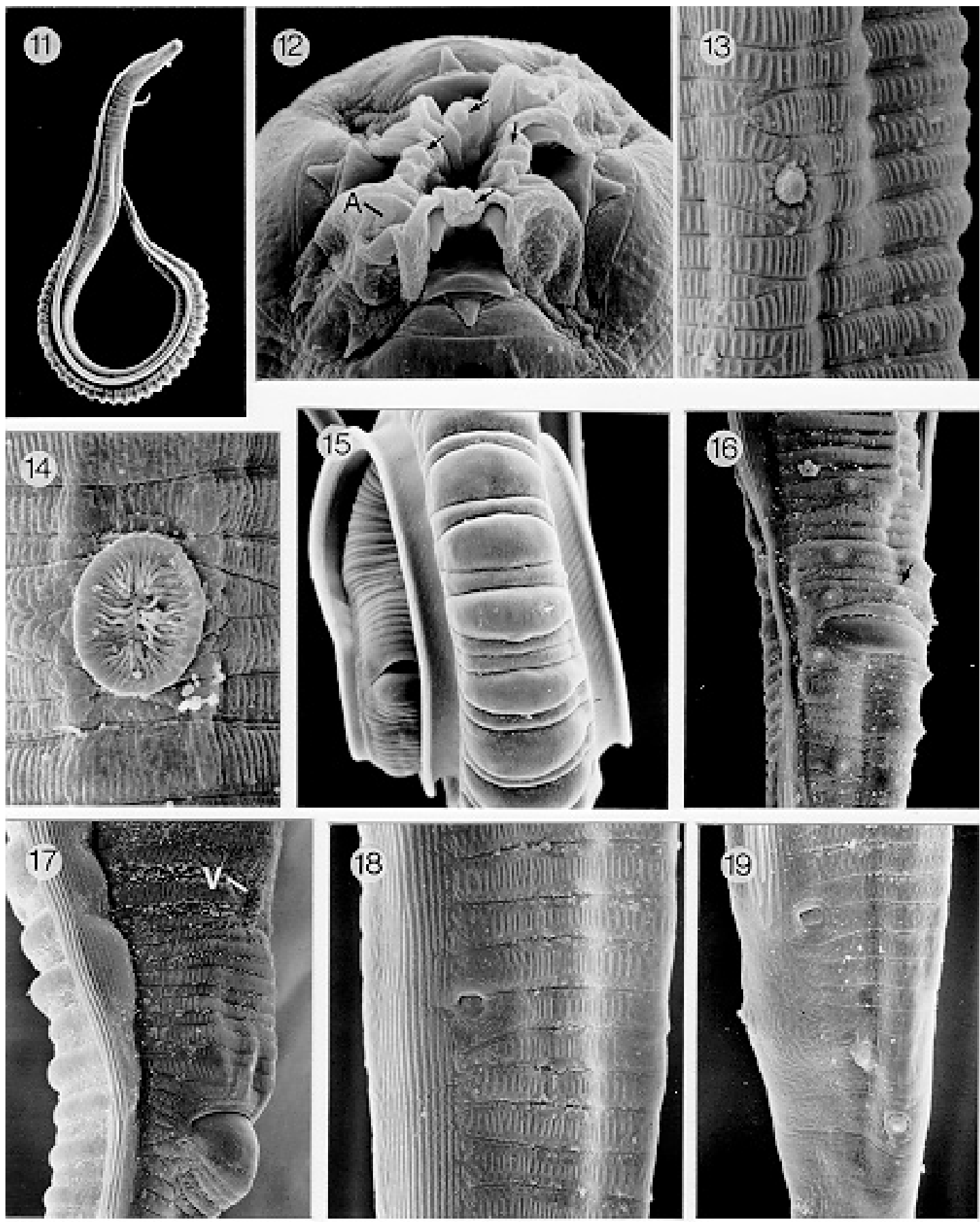

Figs 11-19: Paraorientatractis semiannulata n. g., n. sp., scanning electron microscopy. 11: complete female, lateral view. 12: en face view showing papillae of inner circle of cephalic sensory organs (arrowed) and position of amphidial pore (A). 13: one of cervical papillae. 14: excretory pore. 15: dorsal surface of female showing semiannules and shape of lateral alae. 16: ventral view of cloacal region of male showing papillae, median precloacal papilla arrowed. 17: lateral view of female vulvar region showing small vulva (V) and large anus. 18: one of phasmids on tail of female. 19: one of phasmids on male tail near two most distal papillae. Scale bar: 11: $27 \mu \mathrm{m} ; 12: 6 \mu \mathrm{m} ; 13: 8 \mu \mathrm{m} ; 14: 6 \mu \mathrm{m} ; 15: 51 \mu \mathrm{m} ; 16: 27 \mu \mathrm{m} ; 17: 25 \mu \mathrm{m} ; 18: 9 \mu \mathrm{m} ; 19: 12 \mu \mathrm{m}$. 
precloacal ventral pairs; one precloacal latero-ventral pair; single median precloacal; two ventral pairs immediately postcloacal, one pair latero-ventral and one ventral pair just posterior to end of lateral alae, phasmids opens at level of distal end of lateral alae; tail $0.64-0.74$ long.

Female: body 1.79 - 2.55 long, 0.045 - 0.062 wide at level of the vulva; head $0.028-0.038$ wide; excretory pore, cervical papillae and nerve ring 0.24 - 0.30, $0.142-0.185$ and $0.15-0.19$ respectively; anterior muscular oesophagus $0.118-0.159$ long, posterior glandular oesophagus 0.175 - 0.248 long; large half annules on the dorsal surface commence $0.115-0.163$ from anterior end and extend to 0.126 - 0.180 posterior to anus; lateral alae arise 0.102 0.241 from anterior and finish $0.03-0.16$ posterior to anus; vulva opens $0.555-0.845$ from tail tip; phasmids opens near distal end of lateral alae; tail $0.52-0.80$ long.

\section{DISCUSSION}

The specimens described here are assigned to the Atractidae (Railliet, 1917 subfam.) Travassos, 1919 because the oesophagus is clearly divided into two parts, the posterior part with a distal bulb and valve, the male is without a precloacal sucker, two spicules and a gubernaculum are present, the vulva is situated in the posterior part of the body and the female tail is pointed. The family Atractidae, at one time placed in the Oxyuroidea, was considered by Chabaud and Petter (1960) to be nearer the Cosmocercoidea and this is now generally accepted. Chabaud (1978) accepted 20 genera in the family Atractidae. Adamson and Baccam (1988) accepted 14 genera moving 5 genera to the Cosmocercidae. Khalil and Gibbons (1988), Gibbons et al. $(1995,1996)$ added three more genera to the family Atractidae, namely, Buckleyatractis, Podocnematractis and Diceronema respectively. The specimens described herein show some similarities to the genera Orientatractis Petter, 1966 and Proatractis Caballero, 1971. Petter (1966) erected Orientatractis for specimens described from Testudo elongata from the Botanical Gardens of the Institut Pasteur of Saigon and designated $O$. levanhoai as type species. Five males and three females of the type specimens, collection number $94 \mathrm{Q}$, were made available to the writers by the Museum National d'Histoire Naturelle, Paris for examination. The genus is characterized by complex structures on the apical extremity, the presence of 2 lateral lips and 4 submedian lips with chitinous elements, oesophagus divided into two parts, 2 unequal spicules and a gubernaculum, females monodelphic, vulva situated near anus, uterus with numerous larvae and parasitic in reptiles. Buckley (1969) added a second species to the genus, Orientatractis leiperi from Podocnemis vogli in Colombia. Reviewing the literature on the genus and examination of the type specimens of $O$. levanhoai confirms that the present specimens differ considerably in appearance from the two species of Orientatractis. They differ from both the species of the genus in the absence of the four bicornate structures on the cephalic region ( the present specimens have a pair of recurved spines which appear to join near their distal margin), the absence of the two lateral lips (only four submedian lips present in the specimens described herein) and the presence of ornamentation on the dorsal surface of the body (absent in the other two species). The present specimens differ from $O$. levanhoai in the presence of lateral alae, the width of the body in the region of the vulva, the size of the vulva opening and the arrangement of the male caudal papillae (three pairs precloacal and five pairs postcloacal in $O$. levanhoai, four pairs precloacal with a single median precloacal papilla and four pairs postcloacal in the specimens described). They differ from $O$. leiperi in the cephalic region (flattened in O. leiperi with six lips, mouth with irregular four-sided border, domed in the specimens described with protruding lips to form a funnel-shaped mouth opening), the cephalic region (narrowing anteriorly in $O$. leiperi and slightly wider than adjacent cervical region in the specimens described), the shape of the lateral alae in cross section (rounded in $O$. leiperi and elongate and curved dorsally in the specimens described) and the male caudal papillae (three pairs precloacal with a single median papilla just anterior to the cloaca and six pairs postcloacal in $O$. leiperi, four pairs precloacal with a single median papilla just anterior to cloaca and four pairs postcloacal in the specimens described).

Caballero (1971) erected Proatractis for specimens recovered from Staurotypus triporcatus Wiegman, 1828 in the southeast of Veracruz, Mexico and assigned to the species $P$. parvicapiticoronata. In spite of a request for the examination of the type specimens unfortunately no specimens have so far been made available to us for study. However based on the original description of the genus the specimens described herein differ from the genus Proatractis in the presence of well developed lateral alae (absent in Proatractis), the number and arrangement of the spines on the cephalic region, the presence of the half annules on the dorsal surface of the body (absent in Proatractis), the number of pairs of male caudal papillae and their arrangement (eight in the present specimens, nine pairs in Proatractis), the shape of the gubernaculum and the difference in 
size of the vulvar opening and anus (small vulva which is difficult to see and a large anus in the present specimens and a large vulva and small anus in Proatractis).

The specimens described differ from all the other species of the family Atractidae in the morphological features of the cephalic region, the half annules on the dorsal surface of the body and the striated lateral alae. For these reasons a new genus has to be erected to accomodate them for which the name Paraorientatractis is proposed and a new species $P$. semiannulata.

Type species: Paraorientatractis semiannulata $\mathrm{n}$. sp.

Type host: Podocnemis unifilis Troschel,1848

Site: large intestine

Locality: Cuminá and Trombetas rivers near Pará, Brazil

Type material: Helminth Collection of the International Institute of Parasitology, St Albans, Herts AL4 0XU, UK, holotype number B1063A, paratypes B1603B, S1094B.

\section{ACKNOWLEDGEMENTS}

To Dr A Petter of the Museum National d'Histoire Naturelle, Paris for making available type specimens of Orientatractis levanhoai for examination and Mr Richard Tranfield of the International Institute of Parasitology for his assistance with the preparation of the scanning electron micrographs.

\section{REFERENCES}

Adamson ML, Baccam D 1988. Systematic position of the Atractidae sensu Chabaud (1978) (Nematoda: Cosmocercoidea): Maracaya belemensis $\mathrm{n} . \mathrm{sp}$. and Aplectana albae n. sp. from Amphisbaena alba in Brazil. Can J Zool 66: 1857-1864.

Alho CJR 1964. Sôbre uma nova espécie do gênero Klossinema Costa, 1961 (Nematoda). Atas Soc Biol Rio de J 8: 1-4.

Baker MR 1987. Synopsis of the Nematoda parasitic in amphibians and reptiles. Memorial University of Newfoundland occasional papers in biology No. 11, $325 \mathrm{pp}$.

Buckley JJC 1969. On a remarkable oxyurid nematode, Orientatractis leiperi n.sp., (Atractidae) from South American tortoise, Podocnemis vogli. J Helminth 43: 281-286.

Buckley JJC 1970. Two remarkable nematodes from a South American tortoise. Trans R Soc Trop Med Hyg 64: 25 .
Caballero GR 1971. Contribución al conocimiento de los nemátodos que parasitan a los reptiles de México. I. Descripción de Proatractis parvicapiticoronata $\mathrm{n}$. g., n. sp., parásito de testudines. Rev Bio Trop 18: 149-154.

Chabaud AG 1978. Key to the genera of the superfamilies Cosmocercoidea, Seuratoidea, Heterakoidea and Subuluroidea, In RC Anderson, AG Chabaud, S Willmott (eds), CIH Keys to the nematode parasites of vertebrates. Farnham Royal: Commonwealth Agricultural Bureaux, No. 6, 71 pp.

Chabaud AG, Petter AJ 1960. Sur les nématodes Atractidés. Libro Homenaje al Dr Caballero y Caballero, Jubilo 1930-1960. Mexico City, Instituto Politechnico Nacional, p. 465-470.

Diesing KM 1851. Systema Helminthum, vol. 2, 588 pp.

Gibbons LM, Khalil LF, Marinkelle CJ 1995. A new nematode genus, Podocnematractis, for Atractis ortleppi Thapar, 1925 (Cosmocercoidea, Atractidae) and the description of another new species, $P$. colombiaensis for Podocnemis spp. in Colombia. Syst Parasit 30: 47-56.

Gibbons LM, Knapp SM, Krecek RC 1996. Diceronema versterae gen. n., sp. n. (Atractidae: Cosmocercoidea) from the Black Rhinoceros, Diceros bicornis bicornis, in South Africa. J Helmintol Soc Wash 63: 98-104.

Gomes DC, Kohn A 1970. Sôbre a subfamilia Ancyracanthinae Yorke \& Maplestone, 1926 (Nematoda, Spiruroidea). Atas Soc Biol Rio de J 13: 83-88.

Khalil LF, Gibbons LM 1988. Two nematodes, Paratractis hystrix (Diesing, 1851) and Buckleyatractis marinkelli n.g., n.sp. (Atractidae: Cosmocercoidea) from Podocnemis spp. in Colombia. Syst Parasit 12: $187-198$

Petter AJ 1966. Equilibre des espèces dans les populations des nematodes parasites du colon des tortues terrestres. Mém Mus natn Hist nat, Paris, Sér A. Zool, 39: 1-252.

Ribeiro DJ 1941. Pesquizas helmintólogicas realisadas no Estado do Parà. VIII. Camallanus amazonicus n. sp. parasito de Podocnemis expansa (Schw.). Mem Inst Oswaldo Cruz 35: 723-727. [In: Baker, 1987]

Sarmiento L 1959. Description of Paratractis hystrix (Diesing, 1851) gen. nov. (Nematoda: Atractidae) from Podocnemis dumeriliana. J Parasit 45: 65-68.

Thapar GS 1925. Studies on the oxyurid parasites of reptiles. J Helminth 3: 83-150.

Travassos L, Freitas JFT de 1964. Pesquisas helminthologicas realizadas em Maicuru, Estado do Pará. Publições avuls Mus Paraense E Goeldi, No. 2, 16 pp. 